\title{
The Empirical Research on Independent Innovation Competencies of Enterprise R\&D Departments
}

\author{
Changnian Liu ${ }^{1}$, Jie Feng ${ }^{1} \&$ Faxin Cheng ${ }^{1}$ \\ ${ }^{1}$ School of Management, Jiangsu University, Zhenjiang, China \\ Correspondence: Jie Feng, School of Management, Jiangsu University, Zhenjiang, 212000, China. Tel: \\ 86-157-5101-1200. E-mail: 2375323892@qq.com
}

Received: April 13, 2015 Accepted: August 3, 2015 Online Published: September 8, 2015

doi:10.5539/ass.v11n26p95 URL: http://dx.doi.org/10.5539/ass.v11n26p95

\begin{abstract}
The strength of the independent innovation competencies of enterprise R\&D departments (hereinafter referred to as ERDD) decides the market competitiveness of enterprises. It is of vital importance to evaluate the innovation competencies of ERDD. Given to the characteristics of ERDD in China, this paper builds the evaluation index system of the independent innovation competencies of ERDD which is based on factor analysis and aimed to understand the corresponding strength of industrial enterprises of the whole country and every province and city clearly. In this paper, 16417 ERDD in Jiangsu province are analyzed. Firstly, their overall situation and dynamic changes of quantities, innovation input and output, platform stimulating effect are analyzed. Secondly, the dynamic changes of constituent elements on their independent innovation competencies are researched. Thirdly, the comparison and evaluation of their independent innovation competencies are carried out by the results of 31 provinces' ERDD in mainland China.
\end{abstract}

Keywords: enterprise R\&D departments, empirical research, independent innovation competencies evaluation

\section{Introduction}

ERDD are not only the main strength of enterprise' independent innovation, but also an important part of regional innovation system. The quantity and quality of ERDD not only determines the enterprises' competencies of independent innovation, but also regional innovation ability, in a great extent, even the country's innovation ability. Many countries and enterprises pay more attention to the construction of high-level R\&D departments, regard them as the strategic move to master the core technologies, maintain the competitive advantages and achieve sustainable development. There are some typical high-level ERDD, such as Bell laboratory in communication industry, DuPont laboratory in chemical industry, Intel laboratory in IT industry, Microsoft Research Institute and other research institutions. The successful construction of the high-quality ERDD provides new products and new technologies for the global markets and builds an unique competitive advantage for the enterprises, even becomes the backbone of the national core competitiveness. Therefore, it is critical to evaluate the competencies of independent innovation of ERDD under the constraints of new economic and technical variables in China. However, the current studies on the independent innovation competencies of ERDD are concentrated more on the R\&D input intensity, the R\&D financing and policy supporting, but less on the evaluation. In view of these deficiencies, some beneficial explorations are carried out in this paper.

\section{Present Actuality and Review of Domestic and Foreign Studies}

So few achievements of the independent innovation competencies of ERDD have been gained and consensus has not been reached. At present, researches of domestic and overseas scholars about the evaluation of innovation competencies of ERDD are mainly concentrated on two aspects: how to establish the evaluation index system and how to choose evaluation method.

There are some typical studies. Foreign scholars analyzed the influence of foreign ERDD on Chinese native enterprises' organization management, policy and other aspects, then put forward to construct innovation competencies evaluation index from three aspects, including transformation of technology, organization management and policy support (Zedtwitz \& Maximilian, 2004). Researchers also supported using 4 indicators: the R\&D input, number of patent applications, patents being cited and new products released, evaluated the innovation competencies of $R \& D$ departments through the analysis of the 1200 international companies chose 
from 4 high-tech industries (Hagedoom \& Cloodt, 2003). The innovation competencies evaluation model of software industry can be structured from the enterprise capacity, output and performance (Edison, Ali, \& Torkar, 2013). Thirteen indexes were selected from several aspects, including the research and development ability, mechanism and system and the work performance, then, fuzzy comprehensive evaluation method was used to evaluate the innovation competencies of ERDD (Sun, 2008). Chinese scholars selected 17 indexes from the innovation ability of input, investment carrier, output and environment to construct the measurement index system, calculated and compared the innovation competencies of R\&D departments in 31 regions of China with the osculating value method (Liu, Sun, Tao, \& Wu, 2008). Recently, large and medium-sized industrial ERDD in various provinces and cities nationwide had been taken as research objects and the index system of evaluating competitiveness was constructed from the innovation input, innovation implementation, innovation environment and innovation output, then measured by factor analysis method (Xia \& Li, 2014).

Some conclusions can be summarized according to above presentation. The theory researches about the evaluation of innovation competencies of ERDD emphasize large and medium-sized enterprises rather than small and micro-sized enterprises, construct the static index rather than dynamic change of enterprise innovation competencies. Empirical researches mostly focus on the overall innovation competencies of regional R\&D departments rather than the evolution of accumulation and improvement of sample ERDD independent innovation competencies. These deficiencies lead to the lack of reflecting their real competencies. Given to these, in this paper, factor-analysis evaluation method is used to construct the evaluation index system of innovation competencies of ERDD, and 16417 industrial ERDD in Jiangsu province are taken as the main research objects to analysis their dynamic changes of constituent factors of innovation competencies and ERDD innovation competencies of Jiangsu province is compare with other 30 regions in mainland China.

\section{Construction of Evaluation System of the Independent Innovation Competencies of ERDD}

Studies have shown that it is difficult to obtain satisfactory results if only single evaluation index system be used in evaluation. For this reason, this paper combines qualitative evaluation with quantitative evaluation, bases on the principles--objectivity, dynamic, feasibility, operability and measurement--to select evaluation indexes from the innovation input, innovation behavior, innovation support and innovation output. Then, eliminating the variable whose variation coefficient is less than 0.5 through variation coefficient analysis. Finally, getting the evaluation index system which consists of 30 indicators. The index system of the evaluation is given in Table 1 .

Table 1. Evaluation system of the independent innovation competencies of ERDD

\begin{tabular}{|c|c|}
\hline First Grade Index & Second Grade Index \\
\hline \multirow{4}{*}{ Innovation } & $\mathrm{R} \& \mathrm{D}$ internal expenditure $\left(\mathrm{X}_{11}\right)$ \\
\hline & R\&D external expenditure $\left(\mathrm{X}_{12}\right)$ \\
\hline & R\&D investment intensity $\left(\mathrm{X}_{13}\right)$ \\
\hline & R\&D personnel FTE $\left(\mathrm{X}_{14}\right)$ \\
\hline \multirow[t]{2}{*}{ Input } & Instrument and equipment value $\left(\mathrm{X}_{15}\right)$ \\
\hline & Expenditure for developing new products $\left(\mathrm{X}_{16}\right)$ \\
\hline \multirow[t]{4}{*}{$\mathrm{X}_{1}$} & $\mathrm{R} \& \mathrm{D}$ projects expenditure $\left(\mathrm{X}_{17}\right)$ \\
\hline & Costs of staff service $\left(\mathrm{X}_{18}\right)$ \\
\hline & Number of $R \& D$ projects $\left(\mathrm{X}_{21}\right)$ \\
\hline & Number of ERDD $\left(\mathrm{X}_{22}\right)$ \\
\hline \multirow[t]{2}{*}{ Innovation } & Enterprise capital expenditure $\left(\mathrm{X}_{23}\right)$ \\
\hline & Other capital expenditure $\left(\mathrm{X}_{24}\right)$ \\
\hline \multirow[t]{2}{*}{ behavior } & Government capital expenditure $\left(\mathrm{X}_{25}\right)$ \\
\hline & Number of new product development projects $\left(\mathrm{X}_{26}\right)$ \\
\hline \multirow[t]{4}{*}{$\mathrm{X}_{2}$} & Number of enterprises with $R \& D$ departments $\left(X_{27}\right)$ \\
\hline & Expenditure for buying domestic technologies $\left(\mathrm{X}_{28}\right)$ \\
\hline & Expenditure for technological transformation $\left(\mathrm{X}_{29}\right)$ \\
\hline & Number of foreign technology $\quad$ import $\quad$ contracts $\left(\mathrm{X}_{31}\right)$ \\
\hline Innovation & Number of high-tech industrial investment completed or put into production items $\left(\mathrm{X}_{32}\right)$ \\
\hline
\end{tabular}




\begin{tabular}{cl}
\hline \multirow{3}{*}{ Support } & Technology import expenditure $\left(\mathrm{X}_{33}\right)$ \\
& Number of college graduates $\left(\mathrm{X}_{34}\right)$ \\
& Number of college staff $\quad\left(\mathrm{X}_{35}\right)$ \\
& Expenditure for digestion and absorption $\quad\left(\mathrm{X}_{36}\right)$ \\
& Number of main foreign retrieval tools included technical papers $\left(\mathrm{X}_{37}\right)$ \\
\cline { 2 - 2 } Innovation & Invention patent applications accounted for the total $\left(\mathrm{X}_{41}\right)$ \\
& Effective invention patents $\left(\mathrm{X}_{42}\right)$ \\
Output & Sales revenue of new products $\left(\mathrm{X}_{43}\right)$ \\
& Sales revenue of new products accounted for the main business income $\left(\mathrm{X}_{44}\right)$ \\
& volume of high-tech products $\left(\mathrm{X}_{45}\right)$ \\
\hline
\end{tabular}

\section{Empirical Analysis}

\subsection{Sample Selection}

In order to promote the construction of ERDD, Jiangsu province has put forward the development strategy named "double promotion, double push" and took the construction of R\&D departments as a strategic opportunity to improve the regional independent innovation competencies. It has continuously strengthened the status of enterprises technological innovation and achieved remarkable results (The People's Government of Jiangsu Province, 2012) . By 2012, the innovation competencies of Jiangsu province was the best of the whole country's during 4 years continuously. The quantity and quality of ERDD have improved greatly. Therefore, this paper studies enterprises in Jiangsu province empirically.

\subsection{The Basic Situation of the Sample Enterprises}

\subsubsection{The Basic Construction Situation of Jiangsu Province Industrial ERDD}

1) The number and growth of industrial ERDD in Jiangsu province

By the end of 2012, Jiangsu industrial enterprises had 16417 R\&D departments, accounted for $35.50 \%$ of the country's gross; the number of the industrial enterprises which own R\&D departments accounted for $37.70 \%$ of the country's gross; 2010 to 2012 year, the average annual growth rate of large and medium-sized industrial enterprises which have their own R\&D departments had reached 85.24\%. From the perspective of ERDD built rate, industrial R\&D departments built rate reached $32.00 \%$; large and medium-sized industrial ERDD built rate reached as high as $75.00 \%$, nearly 40 percentage points more than the end of the 11 th five-year plan, including large and medium-sized enterprises' reached $80.00 \%$ and $74.00 \%$; R\&D departments built rate of high-tech industrial enterprises reached $94.70 \%$.

2) Innovation investment and growth of Jiangsu province industrial ERDD

By the end of 2012, industrial ERDD of Jiangsu province above designated size had spent 108.03 billion yuan in $\mathrm{R} \& \mathrm{D}$, accounted for $15.00 \%$ of the country's, increased nearly 2.27 percentage points than the end of the 11th five-year plan. Average annual growth rate of large and medium-sized industrial enterprises' R\&D expenditure reached $25.60 \%$ between 2010 to 2012. Industrial ERDD of Jiangsu province above designated size had 48.32 ten thousand researchers with the average annual growth of $28.30 \%$ that accounted for $21.30 \%$ of the country's, increased 113.85 thousand than the end of 2010 and 0.85 percentage points more than the end of the 11th five-year plan.

3) Innovation output and growth of Jiangsu province industrial ERDD

By the end of 2012, Jiangsu industrial enterprises carried out 44570 R\&D projects with the average annual growth of $75.10 \%$ and increased nearly 3.26 percentage points than the end of the 11 th five-year plan, including the number of industrial enterprises with $\mathrm{R} \& \mathrm{D}$ departments that accounted for more than $60.00 \%$ of all with the average annual growth rate of $39.00 \%$. Industrial enterprises developed 53973 new products with the average annual growth of $79.64 \%$ that increased 3.65 percentage points than the end of the 11 th five-year plan. Industrial enterprises had new products sales revenues 1784.54 billion yuan that was $4.33 \%$ higher than the end of the 11 th five-year plan, with the average annual growth rate of $53.65 \%$. The industrial enterprises which own R\&D departments achieved 1776.24 billion yuan--income from new products of industrial enterprises--that accounted for $99.50 \%$ of all.

4) Stimulating effect of Jiangsu province industrial ERDD 
By the end of 2012, Jiangsu province had 7216 "university-enterprise alliances" and implemented more than 13000 "industry-university-research projects", participated by more than 340 universities, 3000 disciplinary teams and 37.90 ten thousand scientific and technological personnel. There were more than 1000 new "university-enterprise alliances" with an average annual growth of $38.00 \%$. From the perspective of attracting external resources, the sources of R\&D funds include government funds, enterprise funds, offshore funds and other funds. Enterprise funds account for $95.77 \%$ of the total funds with the average annual growth rate of $23.13 \%$; government funds reached 1.62 billion yuan with the average annual growth rate of $29.00 \%$; offshore funds reached 0.72 billion yuan with the average annual growth rate of $-8.75 \%$; other funds reached 1.06 billion yuan with the average annual growth rate of $22.80 \%$. From the perspective of driving engineering technological investment, big and medium-sized enterprises which have R\&D departments put 58.36 billion yuan into technology transformation with the average annual growth rate of $10.30 \%, 5.35$ billion yuan into technology introduction with the average annual growth rate of $24.20 \%, 2.34$ billion yuan into technology digestion and absorption with the average annual growth rate of $39.40 \%, 2.46$ billion yuan into purchasing domestic technologies with the average annual growth rate of $33.20 \%$.

\subsubsection{Comparative Analysis of the Construction of Jiangsu Province Industrial ERDD}

1) The number and growth of industrial ERDD

By the end of 2012, R\&D departments built rate and the average annual growth rate of Jiangsu province industrial enterprises above designated size both ranked the first that are much higher than Zhejiang, Shanghai and Beijing.

2) Innovation investment and growth of industrial ERDD

By the end of 2012, the total R\&D funds of industrial enterprises in Jiangsu province ranked first, and average annual growth rate ranked the second about 10 percentage points lower than Zhejiang province. From the perspective of R\&D personnel input, Jiangsu province was located in the first, while the R\&D staff growth lagged behind Zhejiang province and Beijing city.

3) Innovation output and growth of industrial ERDD

By the end of 2012, the number of R\&D projects implemented by Jiangsu province industrial enterprises above designated size ranked the top in our country, but the average annual growth rate was lower than Zhejiang province, ranked the second. From the perspective of development of new products and sales, the average annual growth rate of new products and their sales revenue ranked the second and first nationwide. From the perspective of original intellectual property rights, the total and average annual growth rate of patent applications of Jiangsu province industrial enterprises above designated size ranked third and fifth nationwide. Both of the invention patents' quantities and average annual growth rate of Jiangsu ranked first in the whole country, especially transferring and licensing patents accounted for $58.30 \%$ of total innovation patents (Note 1 ).

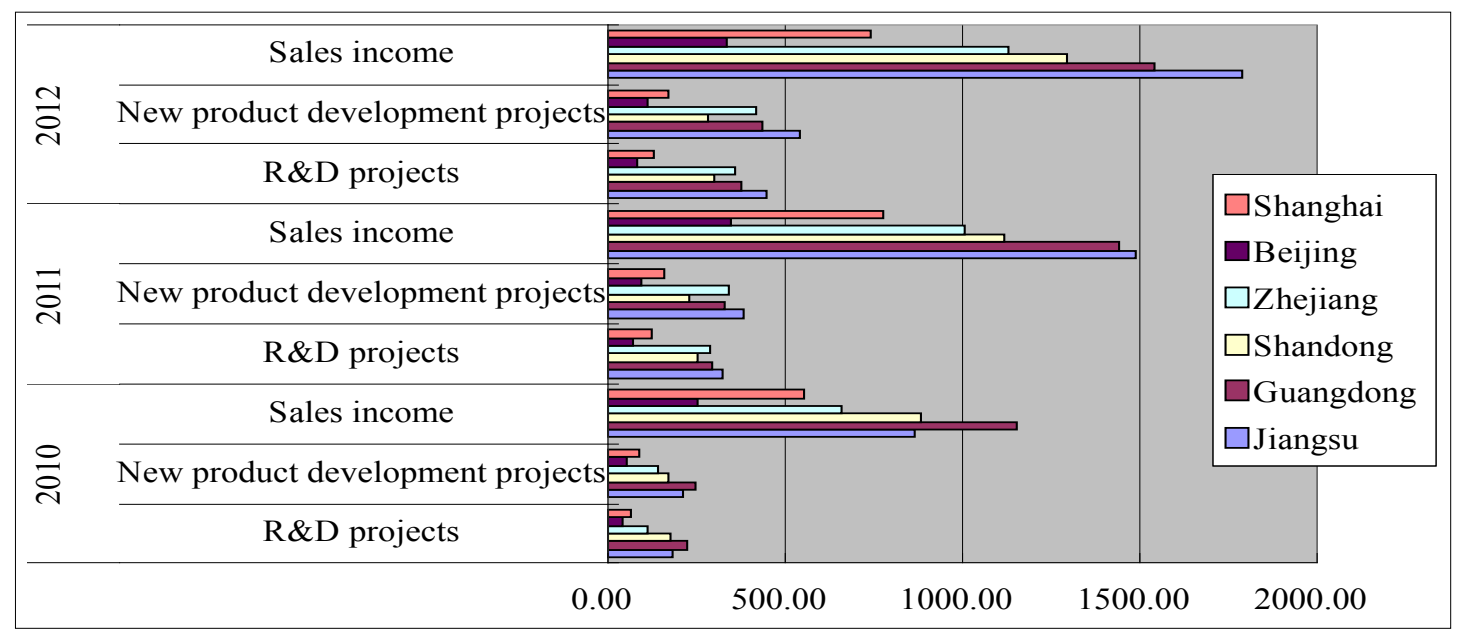

Figure 1. Bar chart of six provinces industrial R\&D departments' R\&D projects, new product development projects and sales income (Note 2) 


\subsubsection{Evaluation of the Independent Innovation Competencies of Jiangsu Province Industrial ERDD}

The original data were normalized in this paper through the statistical program named SPSS20.0, then judged whether it is suitable for factor analysis by the examination of Kaiser-Meyer-Olkin (KMO) and Bartlett value. To extract the main factors with main component analysis method, do factor rotation by the maximum variance method, and use the method of regression analysis to get factor score function $\mathrm{F}_{\mathrm{i}}$,

$$
F_{i}=\sum X_{i j}^{*} W_{i}
$$

get innovation competencies decomposition score, comprehensive score and ranking by using the function $\mathrm{F}\left(\mathrm{W}_{\mathrm{i}}\right.$ is the factor loading weight).

\section{1) Innovation input}

$$
F=\Sigma F_{i}{ }^{*} W_{i}
$$

The result of data analysis shows that KMO is 0.77 , the sphericity test value of Bartlett 625.16 , the level of significance (Sig.) 0.000 , so the data set $\mathrm{X}_{11}-\mathrm{X}_{18}$ is suitable for factor analysis. Two main factors are selected, principal factor $\mathrm{f}_{1}$ and $\mathrm{f}_{2}$ are rotated and their variance contribution rates are $78.83 \%$ and $17.92 \%$, the cumulative variance contribution rate is $94.75 \%$, as shown in Table 2. Getting the corresponding scores and ranking according to the function.

$$
F_{1}=0.7883 f_{1}+0.1792 f_{2}
$$

As shown in Table 3, the innovation input scores of Jiangsu, Guangdong, Shandong, Zhejiang and Shanghai are among the top 5 that highlights their strong investment on the construction of ERDD and their overall scale far beyond any others'. Anhui, Fujian, Henan, Liaoning and Hubei provinces increase significantly in input, however, Guizhou, Xinjiang, Ningxia, Hainan, Qinghai and Tibet the total of 12 provinces are still in the bottom.

Table 2. The rotary component matrix and component score coefficient matrix (Note 3)

\begin{tabular}{ccccc}
\hline & \multicolumn{2}{c}{ The rotary component matrix } & \multicolumn{2}{c}{ Component score coefficient matrix } \\
\cline { 2 - 5 } & 1 & 2 & 1 & 2 \\
\hline R\&D internal expenditure $\left(\mathrm{X}_{11}\right)$ & 0.967 & 0.232 & 0.172 & -0.051 \\
R\&D external expenditure $\left(\mathrm{X}_{12}\right)$ & 0.824 & 0.460 & 0.064 & 0.241 \\
R\&D investment intensity $\left(\mathrm{X}_{13}\right)$ & 0.197 & 0.975 & -0.256 & 0.996 \\
R\&D personnel FTE $\left(\mathrm{X}_{14}\right)$ & 0.966 & 0.164 & 0.193 & -0.125 \\
Instrument and equipment value $\left(\mathrm{X}_{15}\right)$ & 0.900 & 0.187 & 0.169 & -0.079 \\
Expenditure for developing new products $\left(\mathrm{X}_{16}\right)$ & 0.961 & 0.237 & 0.169 & -0.044 \\
R\&D projects expenditure $\left(\mathrm{X}_{17}\right)$ & 0.973 & 0.210 & 0.181 & -0.077 \\
Staff service expenditure $\left(\mathrm{X}_{18}\right)$ & 0.938 & 0.234 & 0.164 & -0.039 \\
\hline
\end{tabular}

2) Innovation behavior

The result of data analysis shows that KMO is 0.86 , the sphericity test value of Bartlett 571.00, Sig.0.000. Therefore, the data set $\mathrm{X}_{21}-\mathrm{X}_{29}$ is suitable for factor analysis. Two main factors are selected. Principal factor $\mathrm{f}_{1}$ and $\mathrm{f}_{2}$ are rotated and their variance contribution rates are $54.02 \%$ and $35.11 \%$, the cumulative variance contribution rate is $89.43 \%$. Getting the corresponding scores and ranking according to the function.

$$
F_{2}=0.5402 f_{1}+0.3511 f_{2}
$$

Looking from the implementation situation over our country, Jiangsu, Zhejiang, Shandong, Guangdong and Shanghai's scores are much higher than others' that these 5 provinces attached more importance to the construction of ERDD and implementation ability, especially higher than other provinces in R\&D projects, department built rate and technology introduction support.

3) Innovation support

The result of data analysis shows that KMO is 0.68 , the sphericity test value of Bartlett is 319.97 , Sig. 0.000 , so the data set $\mathrm{X}_{31}-\mathrm{X}_{38}$ is suitable for factor analysis. Two main factors are selected, principal factor $\mathrm{f}_{1}$ and $\mathrm{f}_{2}$ are rotated and their variance contribution rates are $45.88 \%$ and $37.97 \%$. Getting the corresponding scores and 
ranking according to the function.

$$
F_{3}=0.4588 f_{1}+0.3797 f_{2}
$$

In view of the innovation support all over our country, Jiangsu ranks the first, followed by Zhejiang, Shandong and Guangdong etc. Further analysis shows that Jiangsu province has basically realized full coverage of high-tech ERDD. Besides, it's technological plans tilted the enterprises with R\&D departments, such as the provincial science and technological achievements transform funds, the provincial science and technology infrastructure plan and special funds plan of introduction, digestion and absorption, which has produced an obvious guide and direction effect. Jiangsu province has created the good environment for innovation by promoting the spirit of "innovation, entrepreneur and excellence; to be the first, to be in the lead, to take the lead" vigorously, improving the entrepreneurial innovation consciousness and ability, encouraging college students' entrepreneurial passion and innovation vigor of the whole society.

\section{4) Innovation output}

The result of data analysis shows that KMO, the sphericity test value of Bartlett and Sig. all meet the requirements, so the data set $\mathrm{X}_{41}-\mathrm{X}_{45}$ is suitable for factor analysis. Two main factors are selected, principal factor $f_{1}$ and $f_{2}$ are rotated and their variance contribution rates are $57.20 \%$ and $27.82 \%$. Getting the corresponding scores and ranking according to the function.

$$
F_{4}=0.5720 f_{1}+0.2782 f_{2}
$$

In view of the innovation output all over our country, there is a great gap between Guangdong, Jiangsu, Shanghai, Beijing, Shandong, Tianjin and Zhejiang 7 provinces and cities and others, especially reflected in applications of patent invention, sales revenue of new products and the total import and export trade volume of high-tech products. The ERDD of these 7 provinces and cities have made great progress in many areas, including mastering the key technologies, researching and developing key equipments and high-tech products, improving intellectual property management systems and enhancing the capability of creation and application of intellectual property rights etc. Compared with Guangdong province, Jiangsu province lags behind in the number of effective patents, sales revenue of new products accounted for main business income and the total volume of import and export trade of high-tech products.

\section{5) Overall evaluation}

The result shows that KMO is 0.71 , the sphericity test value of Bartlett 129.31, Sig.0.000 through factor analysis on the innovation input, innovation behavior, innovation support and innovation output, so the whole data is suitable for factor analysis. Two main factors are selected, principal factor $f_{1}$ and $f_{2}$ are rotated and their variance contribution rates are $63.91 \%$ and $37.71 \%$, and the cumulative variance contribution rate reaches $95.62 \%$. Getting the corresponding scores and ranking according to the function.

$$
F=0.6391 f_{1}+0.3771 f_{2}
$$

In the view of the ranking of independent innovation competencies of ERDD, Jiangsu province remains the NO.1 followed by Guangdong, Shandong, Zhejiang, Shanghai and Beijing that highly integrates with the state that their competencies of innovation input, innovation behavior, innovation support and innovation output are all stronger than others'. And these 6 provinces and cites are positioned in the top echelon. Hubei, Anhui, Henan, Liaoning, Sichuan, Shanxi and others total of 12 provinces are located in the second echelon. These 12 provinces have tremendous scope for development because of the quite different competencies with the obvious advantages and disadvantages. Guangxi, Inner Mongolia, Guizhou, Gansu and Tibet and others total of 13 provinces with weak innovation competencies are located in the third echelon that results from the small and weak economic power and underdeveloped construction of ERDD.

Table 3. Industrial ERDD innovation competencies decomposition and comprehensive ranking list of 31 provinces and cities in mainland China

\begin{tabular}{ccccccccccc}
\hline Region & II & R & IB & R & IS & R & IO & R & CS & R \\
\hline Jiangsu & 2.39 & 1 & 2.26 & 1 & 2.06 & 1 & 1.11 & 2 & 2.544 & 1 \\
Guangdong & 2.33 & 2 & 1.01 & 4 & 0.76 & 4 & 2.74 & 1 & 1.728 & 2 \\
Shandong & 1.56 & 3 & 1.02 & 3 & 0.88 & 3 & 0.09 & 5 & 1.22 & 3 \\
Zhejiang & 1.1 & 4 & 1.08 & 2 & 0.93 & 2 & 0.04 & 7 & 0.762 & 4 \\
Shanghai & 0.5 & 5 & 0.25 & 5 & 0.50 & 5 & 0.69 & 3 & 0.690 & 5 \\
\hline
\end{tabular}




\begin{tabular}{|c|c|c|c|c|c|c|c|c|c|c|}
\hline Beijing & -0.11 & 13 & -0.03 & 10 & 0.15 & 10 & 0.46 & 4 & 0.222 & 6 \\
\hline Hubei & 0.02 & 9 & -0.05 & 12 & 0.11 & 12 & -0.14 & 12 & 0.098 & 7 \\
\hline Anhui & 0.03 & 6 & 0.14 & 6 & 0.35 & 6 & -0.27 & 19 & 0.071 & 8 \\
\hline Hunan & -0.07 & 12 & 0.07 & 8 & 0.29 & 8 & -0.07 & 8 & 0.047 & 9 \\
\hline Henan & 0.03 & 8 & -0.05 & 11 & 0.14 & 11 & -0.36 & 25 & 0.046 & 10 \\
\hline Liaoning & -0.04 & 10 & 0 & 9 & 0.26 & 9 & -0.13 & 10 & 0.011 & 11 \\
\hline Sichuan & -0.16 & 15 & -0.06 & 14 & 0.02 & 14 & -0.23 & 18 & -0.004 & 12 \\
\hline Fujian & 0.03 & 7 & 0.07 & 7 & 0.30 & 7 & -0.30 & 22 & -0.055 & 13 \\
\hline Tianjin & -0.06 & 11 & -0.06 & 13 & 0.02 & 13 & 0.07 & 6 & -0.083 & 14 \\
\hline Hebei & -0.13 & 14 & -0.13 & 15 & -0.09 & 15 & -0.35 & 24 & -0.131 & 15 \\
\hline Shanxi & -0.32 & 16 & -0.24 & 16 & -0.11 & 16 & -0.19 & 17 & -0.236 & 16 \\
\hline Jiangxi & -0.38 & 21 & -0.32 & 21 & -0.35 & 21 & -0.29 & 20 & -0.256 & 17 \\
\hline Chongqing & -0.33 & 17 & -0.25 & 17 & -0.15 & 17 & -0.36 & 26 & -0.295 & 18 \\
\hline Jilin & -0.37 & 20 & -0.39 & 26 & -0.53 & 26 & -0.17 & 16 & -0.331 & 19 \\
\hline Heilongjiang & -0.35 & 19 & -0.31 & 20 & -0.24 & 20 & -0.32 & 23 & -0.347 & 20 \\
\hline Shanxi & -0.35 & 18 & -0.26 & 18 & -0.15 & 18 & -0.3 & 21 & -0.368 & 21 \\
\hline Guangxi & -0.43 & 22 & -0.3 & 19 & -0.17 & 19 & -0.14 & 13 & -0.379 & 22 \\
\hline Inner Mongolia & -0.44 & 23 & -0.36 & 23 & -0.39 & 23 & -0.14 & 11 & -0.449 & 23 \\
\hline Yunnan & -0.5 & 24 & -0.37 & 25 & -0.47 & 25 & -0.16 & 15 & -0.462 & 24 \\
\hline Guizhou & -0.52 & 26 & -0.32 & 22 & -0.35 & 22 & -0.08 & 9 & -0.471 & 25 \\
\hline Gansu & -0.5 & 25 & -0.36 & 24 & -0.44 & 24 & -0.43 & 28 & -0.482 & 26 \\
\hline Ningxia & -0.58 & 28 & -0.47 & 28 & -0.66 & 28 & -0.42 & 27 & -0.580 & 27 \\
\hline Hainan & -0.59 & 29 & -0.49 & 29 & -0.68 & 29 & -0.15 & 14 & -0.609 & 28 \\
\hline Xinjiang & -0.53 & 27 & -0.46 & 27 & -0.59 & 27 & -0.69 & 30 & -0.641 & 29 \\
\hline Qinghai & -0.6 & 30 & -0.5 & 30 & -0.70 & 30 & -0.46 & 29 & -0.680 & 30 \\
\hline Tibet & -0.61 & 31 & -0.51 & 31 & -0.72 & 31 & -0.86 & 31 & -0.684 & 31 \\
\hline
\end{tabular}

II: Innovation input, IB: Innovation behavior, IS: Innovation support, IO: Innovation output, CS: Comprehensive score, R: Ranking.

\subsubsection{Analysis of the Existing Problems of Jiangsu Province Industrial ERDD Construction}

1) Some departments have no relevant activities, the operation quality of ERDD needs to be improved

Survey data shows that 4615 Jiangsu province industrial enterprises above designated size which have their own R\&D departments without R\&D expenditure, accounted for $30.80 \%$ of all. Xuzhou, Zhenjiang, Wuxi, Suzhou and Taizhou cities have more than $30.00 \%$ enterprises which have built $R \& D$ departments but failing to carry out $R \& D$ activities, as shown in Table 4. It is a pressing matter to improve their operation quality when the quantity of ERDD has been increased. The date are given in Table 4.

Table 4. The R\&D activities situation of Jiangsu province and its regional industrial enterprises which have R\&D departments without R\&D activities in 2012

\begin{tabular}{cccccccc}
\hline & Jiangsu & Nanjing & Wuxi & Xuzhou & Changzhou & Suzhou & Nantong \\
\cline { 2 - 8 } Count & 4615 & 109 & 910 & 949 & 298 & 1035 & 242 \\
Ratio(\%) & 30.80 & 11.90 & 33.80 & 62.30 & 23.70 & 32.30 & 18.00 \\
\hline & Lianyungang & Huai'an & Yancheng & Yangzhou & Zhenjiang & Taizhou & Suqian \\
\cline { 2 - 9 } Count & 68 & 97 & 115 & 205 & 205 & 197 & 619 \\
Ratio(\%) & 20.90 & 25.90 & 18.60 & 21.60 & 34.00 & 33.40 & 29.90 \\
\hline
\end{tabular}

2) ERDD are small and weak, without global influence

Survey data shows that the average expenditure of Jiangsu province ERDD is 7.23 million yuan which is 4.16 
million yuan lower than the national average level and lagging behind Beijing, Shanghai, Guangdong and Shandong. From the perspective of own hardware, enterprises whose R\&D departments equipment's value are not higher than 0.1 million yuan and 0.05 million yuan accounted for $16.4 \%$ and $10.2 \%$ of all. There are vanishingly rare ERDD with global influence in Jiangsu province.

3) The lack of talents, especially leading talents of high levels

The talents shortage has become one of the restricted factors for construction of high-level R\&D departments. In view of the education composition of employees of ERDD, doctoral students and postgraduates only accounted for $1.80 \%$ and $8.40 \%$. About $25.00 \%$ enterprise departments lack R\&D technical backbone personnel, and $60.00 \%$ enterprise departments lack innovation leading talents. In view of personnel number of per ERDD, the average number of Jiangsu province is 29 that lower than national level (49), Guangdong (99), Shanghai (85) and Beijing (73). Even approximately $20.00 \%$ departments have researchers less than 5 .

\section{Conclusion}

ERDD, as one of sources of independent innovation, have been taken as an "engine" for enterprise's development. In recent years, Jiangsu province actively guides and vigorously promotes the construction of ERDD, and has achieved remarkable results. Jiangsu province ERDD have achieved breakthrough in department built rate and growth. Importantly, Jiangsu province gets great improvement in the competencies of innovation input, innovation behavior, innovation support and innovation output and ranks top in the 31 provinces. Its overall independent innovation competencies of $R \& D$ departments occupies the first place. However, the construction of ERDD still exists quite a few problems, such as poor operation quality, small scale, weak strength, sorely lacking of high levels of leading talents, result in the difficulties to adapt to Jiangsu province strategic requirement which is aimed to take the lead in building innovative province and accelerating the transformation and upgrading of enterprises. Therefore, further strengthening the construction quality of ERDD is an undoubtedly strategic choice in solving this dilemma.

\section{Acknowledgments}

The authors would like to thank for the support by national natural science foundation (grant number: 712731 18): enterprises in low carbon manufacturing strategy formation mechanism and drive model research based on whole life cycle of product, Chinese humanities and social science fund project of education ministry (grant number: 12 YJA6300 69): research on the development mechanism and path choice to upgrade in the transition of small and medium-sized industrial enterprises in China and Jiangsu University senior talents project (grant number: 1281160023$)$.

\section{References}

Edison, H., Ali, N. b., \& Torkar, R. (2013). Towards Innovation Measurement in the Software Industry. Journal of Systems and Software, 86(5), 1390-1407. http://dx.doi.org/ 10.1016/j.jss.2013.01.013

Hagedoom, J., \& Cloodt, M. (2003). Measuring Innovative Performance: Is there an Advantage in Using Multiple Indicators. Research Policy, 32(8), 1365-1379. http://dx.doi.org/10.1016/S0048-7333(02)00137-3

Liu, F. C., Sun, Y. T., Tao, Y. W., \& Wu, H. F. (2008). The measurement and comparison of innovation ability of public research institutions in Chinese areas. Management Review, 20(2), 14-19. http://dx.doi.org/10.14120/j.cnki.cn11-5057/f.2008.02.009

Sun, Y. (2008). Study on fuzzy comprehensive evaluation of enterprises $R \& D$ organization of Dalian (Master's thesis, Liaoning Normal University, Dalian, China). Retrieved from http://www.cnki.net/KCMS/detail

The People's Government of Jiangsu Province. (2012). Government Publication [2012] NO. 58th: Opinons about further strengthening the construction of enterprises $R \& D$ institutions. Retrieved from http://www.jiangsu.gov.cn

Xia, T. S., \& Li, Z. Y. (2014). Competitiveness evaluation of R\&D institutions of nationwide and medium-sized industrial enterprises based on factor analysis. Science \& Technology Process and Policy, 1-7. http://dx.doi.org/10.6049/kjjbydc.2013080037

Zainol, N. R. B., Al-Mamun, A., \& Permarupan, P. Y. (2013). Effects of Demand, Manufacturing Flexibility, Cost and Supply Chain on Product Modularity: A Study in Malaysia. Asian Social Science, 9(17), 167-179. http://dx.doi.org/10.5539/ass.v9n17p167

Zedtwitz, V., \& Maximilian. (2004). Managing Foreign R\&D Laboratories in China. R\&D management, 34(4), 439-452. http://dx.doi.org/10.1111/j.1467-9310.2004.00351.x 


\section{Notes}

Note 1. The sources of data in this section: Chinese Science and Technology Statistics Yearbook 2013, Science and Technology Industrial Enterprises Statistical Yearbook 2013 and China High Technology Industry Statistical Yearbook etc, analyzed by the authors.

Note 2. The unit of "R\&D projects" and "new product development projects": hundred items, the unit of "sales income": billion yuan (RMB).

Note 3. The extraction method: principal component. Rotation method: orthogonal rotation method with Kaiser standard. Rotation convergences after 3 times iteration.

\section{Copyrights}

Copyright for this article is retained by the author(s), with first publication rights granted to the journal.

This is an open-access article distributed under the terms and conditions of the Creative Commons Attribution license (http://creativecommons.org/licenses/by/3.0/). 